\title{
Colorectal cancer screening behaviors among South Asian immigrants in Canada: a qualitative study
}

\author{
Joanne Crawford, Farah Ahmad, Dorcas E. Beaton and Arlene S. Bierman
}

The authors' affiliations can be found at the end of this article.
Received 9 September 2014 Revised 4 February 2015 Accepted 9 April 2015

Joanne Crawford would like to acknowledge the Population Health Improvement Research Network for the Ontario Doctora Student in Population Health Award and the Canadian Association of Nurses in Oncology for the Novice Researcher Grant as they provided partial support of the doctoral research.

\begin{abstract}
Purpose - The purpose of this paper is to gain an in-depth understanding of beliefs, attitudes, and reasons for decision making about colorectal cancer (CRC) screening among South Asian (SA) immigrants.

Design/methodology/approach - Six focus groups conducted in English, Punjabi, and Urdu were held with 42 SA immigrants, 50-74 years old and at average risk for CRC, from November 2012 to May 2013. All focus group discussions were audio-taped and transcribed verbatim. Data analysis used an inductive and systematic approach employing constant comparison techniques.

Findings - Three dominant themes emerged. Beliefs and attitudes towards cancer and screening represented SA immigrant's perceptions that early detection was beneficial; screening was not necessary in the absence of symptoms; cancer was scary; and the loss of previously established bowel practices upon immigration as potential risks for CRC. Knowledge and awareness focused on unscreened participants' cancer stories; screened participants' knowledge of CRC, risk factors, and screening; experiential learning from focus groups; and screened participants' strategies to promote screening. Support and accessibility concentrated on physician support and responsibility to provide information, explanation, and recommend screening to facilitate access.

Originality/value - Findings provide novel insights on socio-cultural context, beliefs, and barriers to CRC screening among SA immigrants. Culturally appropriate community-based strategies included story-telling, the use of social networks, and greater physician engagement. Enhancing collaborative partnerships with physicians and public health may minimize structural barriers and reduce health disparities. Future research could explore effectiveness of outreach strategies including these collaborations.
\end{abstract}

Keywords Health behaviours, Focus groups, South Asian, Colorectal cancer, Early detection of cancer, Immigrant health

Paper type Research paper

\section{Introduction}

South Asian (SA) immigrants represent the largest and most rapidly growing minority population in North America (Ahmad, 2012). In Canada, this population is expected to grow due to immigration policies motivated by the aging population, low birth rates, and need for skilled workers. SA immigrants are a diverse population, and identify ethnic origins from the Indian sub-continent including India, Pakistan, Bangladesh, Sri Lanka, Nepal, and Bhutan, as well as countries including Africa, the Caribbean, and Guyana representing the SA diaspora (Tran et al., 2005). The diaspora denotes individuals whose ancestral origins are from the Indian sub-continent prior to initial migration to countries colonized by the British or French (Ahmad, 2012).

In North America, colorectal cancer (CRC) is the third most common cancer diagnosed and the second leading cause of cancer deaths (Jemal et al. , 2011). The incidence of CRC is lower in the Indian sub-continent compared to western countries. However, the CRC incidence among 
SA immigrants approaches similar rates to western populations with length of time settled. Epidemiological studies have documented CRC as one of the three most common cancers diagnosed among SA immigrants in North America and the UK (Hislop et al., 2007; Hossain et al., 2008; Rastogi et al., 2008). This increased incidence has been attributed to post migration factors such as the adoption of western lifestyles and access barriers to cancer screening (Jain et al., 2005; Quan et al., 2006).

Evidence-based guidelines recommend CRC screening for average risk people 50 years of age and older to reduce mortality and morbidity (US Preventive Services Task Force, 2008). However, screening rates among SA immigrants residing in western countries remain sub-optimal. SA immigrants who have historically low breast and cervical cancer screening rates (Lee et al., 2010a; Quan et al., 2006), also have low rates of CRC screening (Lee et al., 2011; Szczepura et al., 2008). In Canada, CRC screening uptake rates are lower among recent immigrants and individuals residing in low income communities than their counterparts (Honein-Abou Haidar et al., 2013). In addition to the low screening rates, there is a dearth of literature providing an in-depth understanding about the factors that influence uptake of CRC screening among SA immigrants.

Only two qualitative studies conducted in the UK have examined CRC screening behaviours among SA immigrants (Austin et al., 2009; Szczepura et al., 2003). Austin et al. (2009) conducted focus groups with SA immigrants (via interpreters) to explore barriers to flexible sigmoidoscopy screening, and key findings included: lack of knowledge and awareness of CRC, low self-perceived susceptibility to $\mathrm{CRC}$, lack of symptoms, lack of confidence in completing bowel preparation at home, and refusing the test if not recommended by a physician. Focus groups undertaken by Szczepura et al. (2003) found SA immigrants: had low knowledge of CRC and consequences of the disease; found cancer worrisome or fatalistic; lacked concern about their health; or had aesthetic issues with the fecal occult blood test (FOBT). These studies provide useful insights but extrapolating to other countries is full of uncertainty due to different immigration patterns and socio-cultural contexts. To address this gap, an exploratory qualitative study using focus groups was conducted with SA immigrants in Canada to elicit their perspectives of CRC and screening. The overall aim was to develop an in-depth understanding of beliefs, attitudes, and reasons for decision-making in CRC screening.

\section{Methods}

This qualitative study used naturalistic inquiry, which is ideally suited to conducting research with vulnerable communities, such as SA immigrants. Situated in critical social theory, power differences between participants and the investigator was reduced through group dynamics (Lincoln et al., 2011). For instance, research assistants (RAs) were immigrants and/or identified with an ethnic minority community, which enhanced the comfort of participants to have an open dialogue. The investigator was sensitive to and valued the multiple perspectives of SA immigrants (Lincoln et al., 2011). The principal investigator, also an immigrant, has training as a public health practitioner, and acknowledges that both investigator and participants' values are intertwined in the presentation of findings.

The use of focus group methods precipitated the emergence of participant voices and in turn, uncovered socially constructed meaning of experiences with CRC and screening (Lincoln et al., 2011). Focus group methods using open-ended questions assisted participants who knew each other to engage in dialogue that facilitated rich discussions (Lincoln et al., 2011; Morgan and Krueger, 1998), and shared knowledge among participants (Kitzinger, 1994). The "cuing phenomenon" inherent in this method enhanced the investigator's ability to uncover multiple dimensions of participants' perspectives without being intrusive (Kitzinger, 1994). Focus group methods are congruent with critical social theory and fostered empowerment by holding sessions in settings familiar to participants in their language of choice. Research Ethics Board approval was obtained from two affiliated universities.

\section{Setting and participants}

The research was conducted in a mid-sized urban city in Ontario, Canada, with a population of 504,000 (Social Planning and Research Council of Hamilton, 2009), home to a growing immigrant 
population. According to the 2006 census, ethnic minority populations increased by 50 per cent over the previous decade in the city. The primary investigator had previous public health experience and ties with organizations servicing SA immigrants in the city, and thus the rationale for selecting the study location.

Potential participants representing a diverse sample were identified using purposive sampling. Eligibility was established using criteria of: self-identification as SA immigrant male and female 50-74 years of age; average risk for CRC (individuals with no prior personal or family history, no genetic or familial polyposis syndromes, no inflammatory bowel diseases, and no bowel symptoms; Winawer, 2005); permanent resident in Ontario; language spoken (English, Urdu, Punjabi, or Hindi); and origin from the Indian sub-continent or SA diaspora. Screened (using FOBT, flexible sigmoidoscopy, or colonoscopy) and unscreened participants were eligible. Temporary or visiting SA immigrants were excluded.

\section{Procedures}

Participant recruitment capitalized on pre-established collaborative relationships with geographically dispersed agencies and used multiple recruitment strategies. Several key stakeholders encompassing six community-based agencies and a public health unit collaborated on the recruitment strategy. Three temples and two community centres serving SA immigrants were recruitment sites where focus groups were held. The primary investigator and male (two) and female (one) multilingual RAs proficient in English, Hindi, Urdu, and Punjabi made repeated visits to sites during group activities to recruit potential participants. Eligible participants registered for a focus group booked around weekly activities or prayers at each site. Urdu and Punjabi advertisements posted at selected sites during this time period were not as successful on their own to recruit participants.

Initially, focus groups were to be stratified by gender and CRC screening status but this was not achieved in the field due to the availability of participants on specific days. Each recruitment site was made up of pre-established groups and thus, potential participants were familiar with each other. Consequently, mixed focus groups (men and women; screened and unscreened) were agreeable to all participating together in the same group, and generated rich discussions.

The development of an open-ended focus group interview guide was informed by the Behavioural Reasoning Theory (Westaby, 2005) with an emphasis on both behavioural constructs and social context; both of which are essential to the assumptions underpinning critical social theory. The interview guide (Appendix) was developed in English, translated into Punjabi and Urdu; each language translation and back translation involved two RAs fluent in English, Punjabi, and Urdu (Esposito, 2001). In the case of any discrepancies, RAs discussed issues and reached consensus. The guide was piloted with four SA immigrants and conceptual revisions made accordingly. Four focus groups were conducted in English with interpretation facilitated by RAs as needed; one focus group was conducted in Punjabi and another in Urdu.

Six focus groups with 42 SA immigrants were held from November 2012 to May 2013. Focus groups were on average 70-90 minutes with five to 12 participants per group. Informed consent was provided including asking permission to audio-tape groups. Participants completed a socio-demographic form and data was entered into Microsoft Excel 10. Refreshments were provided and participants received a $\$ 20.00$ honorarium.

\section{Data collection and rigour}

Several strategies were employed to strengthen the rigour and enrich quality of data collection. Two days of training were provided to RAs on focus group and data collection procedures to enhance the process and consistency of data collection (Aday and Cornelius, 2006). Focus groups were audio-taped and transcribed verbatim by RAs in English (Morgan and Krueger, 1998). For focus groups conducted in Punjabi and Urdu, tapes were transcribed and translated by one RA into English, and back translated by the second RA who made comparisons with original transcripts. After each focus group, the RA provided a summary of key points and asked participants for feedback, which served as member-checking (Krueger, 1994). Debriefing among the RA, co-facilitator RA, and investigator captured additional notes regarding unique aspects of focus 
group discussions. Detailed notes obtained during focus groups served as a means to review subsequent focus group data to ascertain when no new data emerged, and saturation was reached, which subsequently occurred after the sixth focus group (Glaser and Strauss, 1967). Additionally, a peer-audit technique was employed where an external researcher reviewed three transcripts to identify categories and themes to compare with those identified by the primary investigator. To organize and manage data, all audio-taped discussions were entered into NVivo version 8.

\section{Data analysis}

An inductive and systematic approach was used to analyze transcribed data and field notes drawing on techniques from grounded theory methods (Glaser and Strauss, 1967; Corbin and Strauss, 2008), and thematic analysis (Braun and Clarke, 2006). The purpose of analysis was to explore participants' beliefs and attitudes, and decision making related to CRC screening. The initial step began with reading through transcripts and notes line by line thoroughly to gain an understanding of data. During this process, memos of initial ideas and phrases were captured on paper (Glaser, 1998). A method of open-coding was used and related to participants' experiences with $\mathrm{CRC}$ and screening. Coding labels were derived from various sources: participants' exact words, researcher developed phrases, or social or human sciences' concepts. Constant comparison was used to label text phrases or sentences with codes and analyze data further (Glaser, 1978). Codes were then reduced by grouping them into broader categories. Refinement of codes and further categorization into themes and sub-themes were represented visually to further analyze inter-relationships. Final interpretation involved linking findings and discussing them in relation to the original research question. The integrative use of member-checking, debriefing, and peer-audit techniques were used to enhance credibility of research findings.

\section{Findings}

Six focus groups with 42 participants were conducted (Table I focus group characteristics). There was a greater proportion of females (62 per cent, $n=26$ ) than males (38 per cent, $n=16$ ). The mean age of participants was 64 years. In total, 69 per cent $(n=29)$ of participants were born in India, 16 per cent $(n=7)$ originated from other countries including Mauritius, Uganda, Kenya, or Africa, and 14 per cent $(n=6)$ were born in Pakistan and Bangladesh. Mean number of years in Canada was 24; 38 per cent had lived in Canada for ten years or less. In all, 48 per cent $(n=20)$ reported being fluent in English. In total, 38 per cent had attained less than a high school education. Almost half (48 per cent, $n=20$ ) lived in households with other members of the family. Most participants had a family physician (88 per cent, $n=36$ ). CRC screening uptake was similar among women and men. Pakistani/Bangladeshi participants reported lower CRC screening

Table I Focus group characteristics

\begin{tabular}{|c|c|c|c|c|c|c|}
\hline $\begin{array}{l}\text { Focus } \\
\text { group no. }\end{array}$ & $\begin{array}{c}\text { Group } 1 \\
(n=5)\end{array}$ & $\begin{array}{c}\text { Group } 2 \\
(n=7)\end{array}$ & $\begin{array}{c}\text { Group } 3 \\
(n=6)\end{array}$ & $\begin{array}{c}\text { Group } 4 \\
(n=12)\end{array}$ & $\begin{array}{c}\text { Group } 5 \\
(n=7)\end{array}$ & $\begin{array}{c}\text { Group } 6 \\
(n=5)\end{array}$ \\
\hline \multicolumn{7}{|c|}{ Age in years } \\
\hline $50-59$ & 0 & 0 & 0 & 7 & 2 & 1 \\
\hline $50-69$ & 3 & 4 & 3 & 5 & 3 & 3 \\
\hline $70-74$ & 2 & 3 & 3 & 0 & 2 & 1 \\
\hline \multicolumn{7}{|c|}{ English language proficiency } \\
\hline Yes & 4 & 5 & 4 & 0 & 3 & 5 \\
\hline No & 1 & 2 & 2 & 12 & 4 & 0 \\
\hline \multicolumn{7}{|c|}{ Country of origin } \\
\hline India & 3 & 3 & 4 & 12 & 2 & 5 \\
\hline Pakistan & 0 & 0 & 0 & 0 & 5 & 0 \\
\hline Other & 2 & 4 & 2 & 0 & 0 & 0 \\
\hline \multicolumn{7}{|c|}{ Colorectal cancer screening } \\
\hline Yes & 1 & 5 & 5 & 4 & 0 & 3 \\
\hline No & 4 & 2 & 1 & 8 & 7 & 2 \\
\hline
\end{tabular}


uptake compared to other participants. Of note, 42 per cent of women had screening for breast or cervical cancer but not CRC (see Table II for participant characteristics).

Three dominant themes emerged from the focus groups (Figure 1). However, the focus of discussions varied by distribution of screened and unscreened participants within each group. For example, in one focus group of mostly screened participants, the discussion centred on strategies to raise awareness of CRC screening in the SA community. In contrast, the focus group that had only unscreened participants discussed their lack of knowledge and need for a physician recommendation.

Themes, sub-themes, and categories are discussed using verbatim quotes to illustrate specific perceptions and experiences followed by parentheses containing focus group number, gender, participant number, and screening status.

Table II Participant characteristics

$n \quad \%$

$n$

Age in years

50 years and older

$50-59$ years

60-69 years

70-74 years

Total

Mean age: 64 years

Gender

Male

Female

Total

Screening status by gender

Screened: Male, 44\%; Female, 42\%

Unscreened: Male, 56\%; Females, 58\%

\section{Country of birth}

India

Pakistan \& Bangladesh

Other: 16\% (Included countries such as:

Mauritius, Uganda, Kenya or Africa)

Total

Years in Canada

10 years or less

$11-19$ years

20-29 years

30-39 years

40 years or more

Total

Mean years: 24 years

Marital status

Married

Widowed

Divorced

Total

Family household

Alone

Partner/spouse

Parents

Other members of the family

Total

$\begin{array}{rr}16 & 38 \\ 26 & 62 \\ 42 & 100\end{array}$

38
62

100

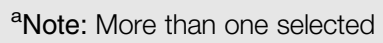

6

14

$7 \quad 16$

$42 \quad 100$
Level of education completed

Less than high school

Completed high school

Completed some college/university

Completed trade, certificate, or diploma

University certificate/diploma

University degree

Post graduate degree

Income status

$<19,999$

20,000-29,999

$30,000-39,999$

$40,000-49,999$

$50,000-79,999$

80,000 or over

Don't know

Total

Family doctor

$29 \quad 69 \quad$ Yes

No

Total

Colorectal cancer screening

Yes

No

18

43

Total

By country of origin

India: Yes, 45\%; No, 55\%

Pakistan/Bangladesh: Yes, 17\%; No, 83\%

Other: Yes, 57\%; No, 43\%

Type of CRC screening

FOBT

17

61

Colonoscopy

11

61

Other cancer screening tests ${ }^{\mathrm{a}}$

Breast

Cervical

PSA

None

$\begin{array}{rr}21 & 41 \\ 9 & 17 \\ 6 & 11 \\ 15 & 31\end{array}$




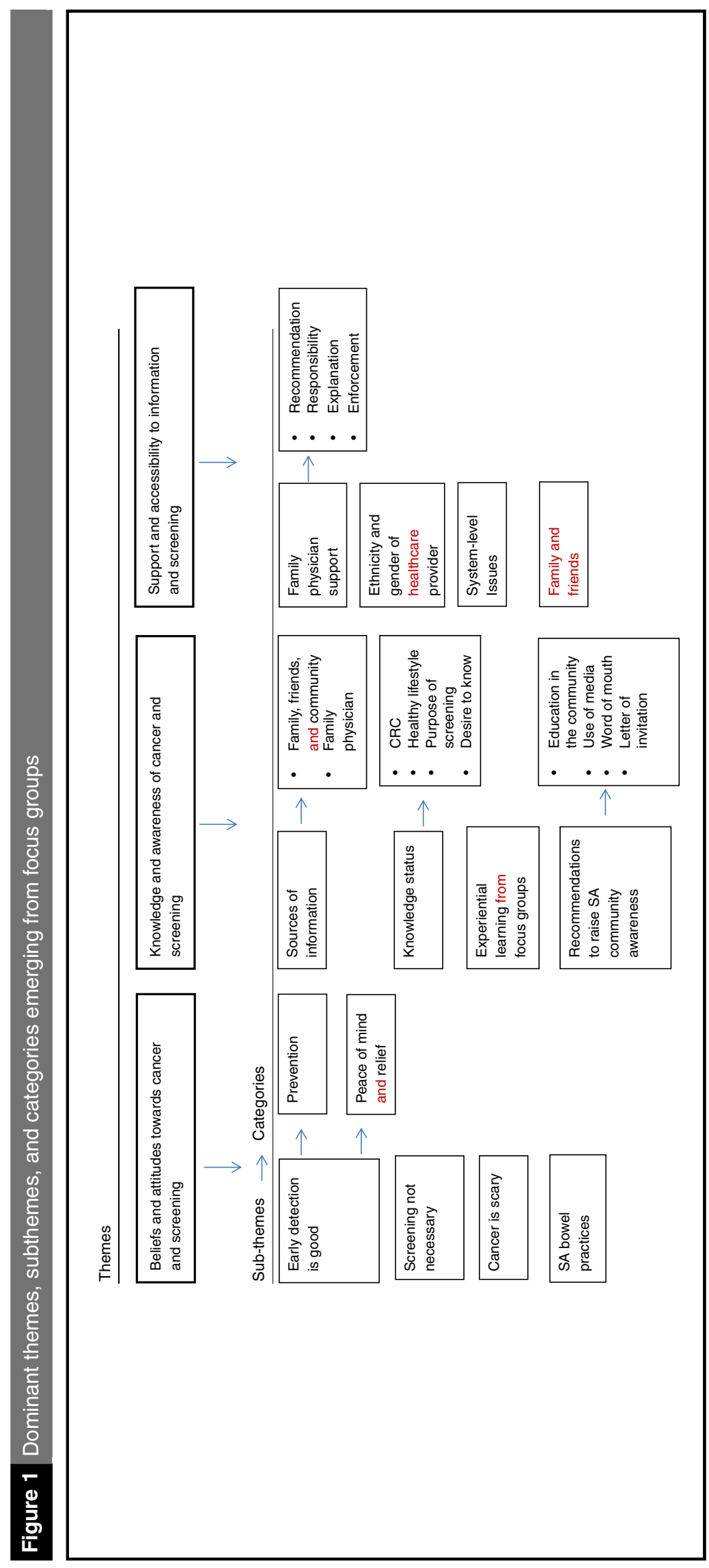

\begin{tabular}{l|l|l} 
VOL 11 NO. 22015 & INTERNATIONAL JOURNAL OF MIGRATION, HEALTH AND SOCIAL CARE & PAGE 135
\end{tabular} 


\section{Theme 1: beliefs and attitudes}

\section{Sub-theme: early detection is good}

Prevention. Across all focus groups, both screened and unscreened participants believed that the detection of $\mathrm{CRC}$ was beneficial to finding a problem and for obtaining early treatment or a potential cure.

Screening was perceived to be important as a preventative measure before cancer advanced and threatened life: "I think it is a very good thing that we do a stool test every two years, at least as a precaution. We can catch the disease in the beginning. It doesn't have to go too far [...] So I think it's a very good thing" (FG 3, Female 6, screened); and, "The test or screening is a good thing that lets us know if we are suffering from the disease [cancer] and then the treatment can be started soon. Not everyone necessarily dies of cancer [...]" (FG 5, Female 7, unscreened).

Peace of mind and relief. Screened participants believed that an advantage of screening was knowledge (i.e. results) that cancer was no longer a threat: "When the test comes back negative, at least you have peace of mind" (FG 2, Female 5, screened); and "You go for any test, if it is negative, you always feel better" ( $F G 3$, Male 5 , screened). For unscreened participants who learned about screening through the focus group, they commented on the sense of "relief", and reduced worry that one would feel if they had screening: "Once you get it done, then at least you won't worry about it. Otherwise, you will continue to worry about it" (FG 1, Female 2, unscreened); "[...] tests made it clear [that you did not have cancer] and you would be relieved if you don't have any complications [...]" (FG 5, Male 1, unscreened).

\section{Sub-theme: screening not necessary}

Some unscreened participants believed that they did not require screening because they did not have symptoms or were healthy. Participants strongly believed they had to have symptoms to warrant a visit to their physician or a screening test. These beliefs were unwavering despite other participants' assertions that CRC screening was important: "I say again, that if there are any symptoms, and you go to the doctor, and he refers you to a test, then I don't have any problems getting it done [...] otherwise, I don't see why" (FG 1, Male 5, unscreened).

The perception of good health and no family history of cancer were other reasons for not believing that CRC screening was necessary: "I don't think I need the test. I stay healthy. Only, if I get any symptoms, only then, will I go for the test" (FG 1, Male 5, unscreened).

\section{Sub-theme: cancer is scary}

Unscreened and screened participants felt that cancer was "scary"; however, for screened participants', fear was associated with having an invasive test or waiting for results. The term, "cancer", itself instilled fear for unscreened participants: "Even the word cancer scares me a little" (FG 2, Female 6, unscreened). The belief that cancer did not have a cure or past experience with others who succumbed to cancer may have led to this perception. Fatalistic beliefs were mentioned in relation to cancer being found in advanced stages. The fear associated with a diagnosis of cancer or even the mention of the word "cancer" was also perceived to bring on illness: "[...] Psychologically, the name of cancer is so scary and upsetting and a person becomes sick and frightened if he has this diagnosis. As far as my opinion is concerned, I believe that a person becomes sick even if comes across the name of cancer" (FG 5, Male 1, unscreened).

\section{Sub-theme: SA bowel practices}

Screened participants in one focus group discussed the aversion to FOBT. The discussion centred on caste systems within one's native country and the process of collecting one's stool. Those in a higher caste perceived handling stool as particularly unpleasant because they were not responsible for manual labour within the home, and therefore less comfortable with stool collection: "It could be that in India, we had a different class [that came in to] clean stools [human waste] in our home, for us. It could be from that we've developed an aversion to it" (FG 3, Female 4, 
screened). Additionally, a lack of proper cleansing after bowel movements was perceived to be a risk for CRC. The act of squatting low to promote complete elimination of feces, and using bidets to cleanse after each bowel movement were important cultural practices: "[...] I think the old fashioned squatting way of eliminating every morning was the best way" (FG 3, Female 2, screened); and, "[...] we from India, are in the habit of washing ourselves when we go to the toilet, you know, we should teach our children. I believe that's a clean habit, rather than letting feces stay on top [of the skin] and be itchy" (FG 3, Female 4, screened).

\section{Theme 2: knowledge and awareness}

\section{Sub-theme: sources of information}

Family, friends, and community. Most participants shared past personal experiences of family or community members who had cancer, the importance of early detection, and the reasons for engaging in CRC screening: "I was perfectly ready to go for it; I said if it would help me and help you to diagnose any problem, sure go ahead. My brother passed away due to lung cancer, so I have seen the bad side of it. I wanted to make sure that cancer did not come into my family basically" (FG 1, Male 3, screened). Narratives of the impact of cancer or poor outcomes were predominant among those who had not heard of CRC: "Only a few days ago, the Imam [Religious Leader] of the Mosque delivered his last sermon and the doctors declared that he had been suffering from cancer [...] He had only a limited period of his life left then [...]" (FG 5, Male 1, unscreened).

Family physician. For some participants, the physician was the most common source to learn about CRC screening: "I think it's very important and my family doctor told me that you should go" (FG 3, Female 3, screened); and, "I think that screening is very important. So, every 2 years, the doctor sends us and we should go to the doctor" (FG 6, Male 2, screened).

\section{Sub-theme: knowledge status}

CRC. Among screened participants, there was greater knowledge of CRC and screening. Knowing about CRC included understanding the implications of the disease, and an enhanced awareness that early treatment would lead to improved outcomes. In contrast, unscreened participants in all groups had limited knowledge of CRC and screening. Some of these participants were hearing about the disease for the first time: "I heard about lung cancer, but I had not ever heard of this CRC that you're speaking of" (FG 2, Female 4, unscreened).

Healthy lifestyle. One focus group with mostly screened participants discussed factors associated with a healthy lifestyle and the linkages to CRC. The adoption of western habits was central to comparisons made between the prevalence of CRC in Canada and SA origin countries. The discussion focused on lifestyle habits such as diet, physical activity, and social support: "I don't hear that much CRC exists in India [...] because people don't eat red meat at all in India" (FG 2, Female 5, screened); and "[...] socialising, people are not as isolated [in India compared to Canada]" (FG 2, Female 2, screened).

Purpose of screening. When asked if participants knew about CRC screening, screened participants had a good understanding of the test and its rationale: "It [FOBT] finds blood that you can't see in the feces. So if you have a lesion somewhere it will come through, you know, and they can pick it out. It could be blood for other reasons also but that sets them [physicians] thinking. And, then you can have more tests" (FG 3, Female 2, screened). In contrast, unscreened participants who heard about screening either knew it was for early detection: "In Punjab, I know they go around and do these tests in many communities. Even if people don't have symptoms, they do them anyway just as a precaution" (FG 4, Male 3, unscreened); or they had no knowledge of the test or the purpose, "We have never heard that there is any test for cancer, except a urine test for bladder cancer, which I came to know about when I came to Canada" (FG 5, Male 4, unscreened), and "For me it is the lack of knowledge. Often, when there is something wrong, we are told to get the test done" (FG 1, Male 4, unscreened). 
Desire to know. Most unscreened participants who had never heard about CRC and screening expressed a keen desire to learn more with only a few who lacked interest. This desire was expressed by further questions: "How do you feel when you have cancer? How do you know [...] what are the symptoms when somebody has this cancer" (FG 4, Female 2, unscreened). Interestingly, there were some screened participants also expressed a desire to know more: "When you do this test and they suspect. What criteria do they use to discover that there is a problem in the colorectal area [...]? What time is the best time for you to get the best specimen" (FG 2, Male 1, screened).

\section{Sub-theme: experiential learning from focus groups}

Sharing of experiences resulted in experiential learning about CRC screening. The influence of others seemed to motivate unscreened participants to ask their physicians about CRC screening. Two participants stated: "Now that I know about it, I will go back [to my family physician] and get it done" (FG 4, Female 8, unscreened); and, "Can you write down the name of this test and I'll go home and get it done" (FG 2, Female 6, unscreened). A number of screened and unscreened participants were also motivated by discussions and thought the investigator was going to provide the test. These perceptions may have been generated by the investigator's presence at recruitment sites several months prior to focus groups: "Yes, we should all get it done. I see that it is beneficial. If you guys do it, then let's get it done" (FG 4, Male 5, screened).

\section{Sub-theme: recommendations to raise SA community awareness}

An unexpected finding was the rich discussions on strategies to raise awareness about CRC screening among screened participants in five focus groups.

Education in the community. Interestingly, when participants were asked what would make it easy for them to participate in CRC screening, screened participants provided suggestions on more public education: "I think community education is important too [...] They could have that [education sessions] at different churches and different temples [...]" (FG 3, Female 2, screened). As well, participants believed that public education was more cost effective than potential cancer treatment: "Its preventative and you know it's going to cost the government less to educate their people than treat them" (FG 3, Female 2, screened).

Some unscreened participants stated they preferred seminars provided by SA community educators to learn about CRC screening: "There is a Pakistani [Peer health educator] woman [...] who used to visit us here. She was very good in terms of telling us what [female cancer screening] tests to do; we need more like her" (FG 4, Female 11, unscreened). Learning through seminars was preferable to reading: "We get good information at this centre. I like hearing the information. Especially medicine related and doctor related. It's easier to understand a person talking about it rather than reading from a book" (FG 2, Female 6, unscreened).

Use of media. Screened participants believed that media could be used to promote education that was contextually relevant and accessible to SA immigrants, such as a cultural newspaper: "If you have read about it, or thought about it, or seen it, the actual cases [CRC in SA immigrants] that have taken place in Canada, then in your mind you think. 'I could be one of them', maybe education?" (FG 1, Male 3, screened). Specific TV and radio programmes were also recommended to increase CRC screening awareness: "Like other media, like doing the radio, some people in Punjabi are doing TV too" (FG 6, Male 2, screened). One participant proposed using a documentary to highlight advanced CRC: "In public education, I think people should be shown what a colostomy looks like and/or ileostomy and the bags [...] If they see all that, then I think they will not [disagree with having the test] [...] Aversion or no aversion, you have to get it done" (FG 3, Female 2, screened).

Word of mouth. Another method of dissemination included using social connections with family and friends to spread the word about CRC screening: "[...] well mostly, when people get together they talk about that [CRC screening]. 'Oh I went for the test and everything is normal [...] you should go'" (FG 3, Male 5, screened); and, "Sometimes friends can inspire each other [to have CRC screening]" (FG 3, Male 5, screened). 
Letters of invitation. Sending letters of invitation to SA immigrants who were due for CRC screening was also proposed by screened participants who were well informed of female cancer screening programmes that used this method: "It's just like mammograms you know; they send you the letter after two years. Then you know you are going" (FG 3, Female 1, screened).

\section{Theme 3: support and accessibility}

\section{Sub-theme: family physician support}

Participant discussions about the family physician were central to support required to gain access to CRC and screening information, a recommendation, and the test.

Recommendation. Screened participants had CRC screening because of a physician recommendation and some were very knowledgeable about age of eligibility, interval timing, and follow - up. A regular check-up with the physician was perceived to be a facilitator to CRC screening: "I found out because of regular doctor's check-ups because he's the one who knows [when the test is due] [...]" (FG 2, Female 2, screened).

Responsibility. The different physician prescribing practices for CRC screening were also mentioned. Several unscreened participants felt it was the physician's responsibility to order the test: "To me, if my doctor sent me, I would have gone. But I will not ask my doctor 'oh I want to go for this' [...] It's the doctor's job to give it to you - [mimicking] 'Okay, now you're old, you should go for this test - mammogram or Pap test'. It's not my job!" (FG 2, Female 3, unscreened). Screened participants also believed the physician was responsible for providing $\mathrm{CRC}$ screening information: "The family doctor should be responsible for disseminating this information [...] Only then will the general population like us find out about it, otherwise, we won't even know that such a test even exists" (FG 4, Female 6, screened). Yet, other participants believed the entire health care team was responsible for enabling access to CRC screening: "I think the main message here is to get these health care providers to have well informed teams who will further inform us about these tests, and recommend it to us in the timely fashion so we get it done" (FG 4, Male 9, screened).

Explanation. While some participants discussed having had CRC screening, it seemed they had some knowledge gaps due to insufficient explanation from their physician: "He didn't say anything. He didn't explain anything. He just said: over 50 years, everybody has to go for this test" (FG 3, Female 3, screened); and, "No, actually, he didn't explain to me anything [about the procedure], but he sent me for the test" (FG 6, Male 5, screened).

Enforcement. A number of participants irrespective of screening status believed the physician should make CRC screening mandatory to increase uptake in their community: "Yeah, doctors should enforce. I think it has to come from enforcement from the doctor" (FG 3, Female 6, screened); and, "Yes, but these doctors need to enforce it and be stricter" (FG 4, Female 11, unscreened).

\section{Sub-theme: ethnicity and gender of health care provider}

A family doctor of the same culture and of the same gender was discussed in two focus groups of primarily screened participants. While cultural understanding was a key aspect in the health care encounter, the ability to converse using the same language was also identified as important: " [...] SA doctors, they can openly say or understand their [SA patients'] feelings. It is not totally clinical; there is an emotional factor. They will explain to them" (FG 2, Male 1, screened); and, "Having a doctor from your own community is better because I don't understand English that well. If it's Hindi language, then I will understand better, especially if it is about medical-related issues" (FG 2, Female 6, unscreened). Among several screened participants, there was a preference for female practitioners because of language and comfort level: "My wife has a different doctor. She has a female doctor and she speaks the same language" (FG 6, Male 2, screened). Screened participants with knowledge of the nurse practitioner role believed they would be ideally suited to provide CRC screening: "They're almost like doctors. A level above the nurse, but below the doctor [...] at least they listen to you, not like the doctors" (FG 2, Female 5, screened). In contrast, 
one participant felt that irrespective of culture or gender, the physician had to be understanding and treat people with respect and dignity: "As long as the doctor is qualified and has his degrees and knows what he's doing. You know, a good doctor. Not like a butcher, you know what I mean. As long as he's showing empathy and listening to you. You're not just a number, you're there as a patient" (FG 2, Female 2, screened).

\section{Sub-theme: system-level issues}

Several participants felt the government should mandate physicians to include CRC screening as part of the renewal process for a driver's license: "I think that is a good idea. For example, making people get the medical test before they renew their driver's license. Or after a certain age, when they are doing their physical, they have to do this test too [...]" (FG 1, Male 4, unscreened).

Time constraints in physician practice were believed to be a source of concern related to being able to ask questions, especially with regards to screening exams. While physicians had the authority to order screening tests and they appeared rushed during a visit, one participant felt adamant that you had to ask about CRC screening: "If you ask them [about the CRC test], you know there's no way they can tell you, 'oh l'm not going to tell you, this is a big secret.' So they have to tell you. So you have to feel important enough. After all, it's your health. So you ask them questions, get them on a paper before you visit the doctor so that even you don't forget it. Because sometimes it's like, you feel uncomfortable because you feel the doctor is in a hurry sort of the moment he comes in, or he comes in, and is kind of trying to see you out" (FG 3, Female 2, screened). Another participant felt that the physician was unable to address multiple issues at one visit, let alone provide screening information: "My family doctor always insists that I can only discuss one issue per visit. She does not want to listen" (FG 5, Female 3, unscreened).

\section{Sub-theme: family and friends}

In all focus groups, participants described the family as a strong support network for health-related appointments. However, close friends were also a support for single participants. Social support included family accompaniment to screening and physician appointments: "[...] My wife and daughter are there, they will support me. My family mostly helped me with the test [...]" (FG 1, Male 3, screened); and, "I have sons who will take me wherever" (FG 4, Female 8, unscreened).

\section{Implications for practice and research}

This study makes new contributions to our understanding of SA immigrant's beliefs, attitudes, and CRC screening behaviours in North America. Three dominant themes related to CRC screening behaviours emerged: Beliefs and attitudes, Knowledge and awareness, and Support and accessibility. The SA immigrants in this study represent the diversity of the population in terms of origin region, religion, education, and socioeconomic status. Consequently, findings reflect differing levels of knowledge of cancer and screening, and screening status. SA immigrants provided insights that elucidated their current understanding of $\mathrm{CRC}$ and screening, which may be useful to inform public health practice to increase uptake.

The positive attitudes towards CRC screening such as "peace of mind" reinforced by screened participants were expected findings given these individuals had a greater knowledge base. These findings align with other CRC screening literature among SA immigrants' in the UK (Austin et al., 2009; Szczepura et al., 2003), other immigrants in the UK (Robb et al., 2008), and African-Americans in the USA (Bauerle Bass et al., 2011). Unscreened participants discussed the relief and decreased worry that would be experienced if one had screening. These findings may have been indirectly influenced by the interaction between screened and unscreened participants during focus groups.

Screened participants provided opinions of personal reasons and perceived benefits of screening, and indirectly role-modelled positive screening behaviours. In contrast, unscreened participants listened to stories, asked questions, and used learning to formulate decisions about screening. The collectivist nature of the SA culture is important since family and close friends provide advice and guidance on decision making related to health (Ahmad et al., 2004; Bottorff 
et al., 2001; Oelke and Vollman, 2007). The social interactions and peer influence within focus groups may have fostered normalization of screening and perhaps reinforced its acceptability. Similar to other ethnic groups, social networking, and community outreach to under-screened persons were strategies proposed by ever-screened African-Americans (Bauerle Bass et al., 2011) or for health promotion among SA immigrant women (Ahmad et al., 2004). Another potential strategy includes the use of peer health educator approaches as they have the potential to increase screening rates among Asian populations, and in turn, may reduce the gap in disparities with screening (Hou et al., 2011). Our study highlights the potential use of story-telling approaches, social networks, and peer influence as feasible health promotion programmes targeting SA immigrant communities.

Several attitudes about cancer and the need for CRC screening were related to a lack of knowledge of prevention or screening, the belief that symptoms had to be present to have a test, and the fear associated with cancer. A lack of knowledge of preventive care and screening among immigrants may relate to the lack of exposure to this concept in countries of origin (Oelke and Vollman, 2007; Lee et al., 2010b). Likewise, the belief that one had to have symptoms or an illness in order to seek out health care or to have screening is a common belief among immigrants (Austin et al., 2009; Lee et al., 2010b). Fear associated with cancer was also identified among unscreened participants, a similar finding observed among SA immigrants in other cancer screening studies (Ahmad et al., 2011; Austin et al., 2009). A novel finding from this study was that several screened participants believed that complete elimination through squatting and cleanliness practices were preventive cultural practices lost upon immigration. These findings highlight the need to incorporate awareness of screening as a form of prevention, cultural beliefs and myths, and $\mathrm{CRC}$ risks when considering strategies to improve $\mathrm{CRC}$ screening uptake among SA immigrants.

Cancer and screening knowledge differed among screened and unscreened participants. Screened participants were more likely to be long-time residents of Canada, have a greater knowledge of $\mathrm{CRC}$, the risk factors and screening, as well as a better understanding of the health care system. Greater years of residence in the host country have been associated with cancer screening uptake (Glenn et al., 2009). Most unscreened participants resided in Canada for a shorter length of time, heard about $\mathrm{CRC}$ and screening for the first time at the focus group, and provided stories of others afflicted with cancer. Even though 90 per cent of participants had a family physician, not all participants had knowledge of CRC or screening. The general lack of knowledge of CRC screening was related to a lack of awareness, or a lack of information or recommendation provided by physicians or other primary health care providers. This is of concern given the evidence-based guidelines for CRC screening (Canadian Task Force on Preventive Health (CTFPHC), 2001; US Preventive Services Task Force, 2008) and the promotion of the population-based screening programme in Canada (Ontario Ministry of Health and Long Term Care (MOHLC), 2012; Cancer Care Ontario, 2014). A lack of knowledge of CRC screening was a common barrier to CRC screening among SA immigrants in the UK (Austin et al., 2009; Szczepura et al., 2003), and for some, there was a reliance on the physician to order the test (Austin et al., 2009). Involvement of the physician in the promotion of cancer screening was similar to our findings, in that it was a recommended method to increase screening knowledge and attendance in other studies (Ahmad et al., 2011; Austin et al., 2009). These findings emphasize the need to use different strategies for recent and established SA immigrants to promote CRC screening, and include physicians in the development of culturally appropriate community-based strategies.

Discussions during focus groups centred on personal knowledge or experiences with cancer, which were important conversations that facilitated learning more about CRC screening. While unscreened participants drew mostly on experiences of other cancers afflicting family, friends or community members, screened participants discussed what they knew about CRC and screening, and answered others questions. The focus group provided a social forum that fostered interaction and learning. Other research has shown that SA immigrants learn about health promotion through social interactions with family, friends, or community (Ahmad et al., 2004; Choudhry, 1998), and peer outreach (Ahmad et al., 2011). For screened participants, they were more vocal in advocating for education strategies to promote CRC screening in their community. Our study findings reinforce others work showing that social networks, community 
leaders, community groups, and seminars involving peer education are culturally appropriate strategies that can be used to disseminate health promotion and cancer screening (breast, cervical, and CRC) information to SA immigrants (Ahmad et al. , 2004; Austin et al. , 2009; Thomas et al., 2005). Places of worship and community centres were identified venues to promote CRC knowledge and screening among SA immigrants, African-Americans, and Spanish immigrants in a number of qualitative studies (Austin et al., 2009; Banning and Hafeez, 2010; Bauerle Bass et al. , 2011; Thomson and Hoffman-Goetz, 2010). Media dissemination including documentaries of people diagnosed with CRC was also a strategy proposed by Spanish immigrants in another CRC screening study (Thomson and Hoffman-Goetz, 2010).

The physician was an important support and mediator to accessing information, and well positioned to listen and encourage participants to obtain screening; a central thread across all themes for screened and unscreened participants. The critical role of a physician recommendation reinforces what others have found in female cancer screening studies among SA immigrant women (Boxwala et al., 2010; Gupta et al., 2002; Somanchi et al., 2010) and CRC screening among SA immigrants and African-Americans (Austin et al., 2009; Bauerle Bass et al., 2011). Preferences for physicians of the same cultural background and/or female gender were also attributes echoed in several screening studies among SA immigrants (Ahmad et al., 2011; Austin et al., 2009; Oelke and Vollman, 2007). These findings point to structural barriers that ought to be addressed by taking a systematic approach to improve access to CRC for multilingual and ehtnic minorities, including SA immigrant communities.

The desire for stricter physician enforcement of CRC screening was also an important finding. The authoritative nature of the physician to recommend cancer screening uptake among SA immigrants has been reported elsewhere (Austin et al. , 2009; Thomas et al., 2005). The CTFPHC (2001) guidelines state that all average risk people 50 years of age and older should have screening using FOBT annually or biennially with colonoscopy follow-up for positive screens, or flexible sigmoidoscopy every five years, or colonoscopy every ten years. While this is best practice based on evidence, screening is voluntary and there is dependence on the physician or other health care provider to recommend screening.

Several screened participants indicated that they did not receive a detailed explanation of CRC screening from their physician, yet they went for screening. Perhaps, simply knowing that $\mathrm{CRC}$ screening is necessary and recommended by one's physician may be sufficient for some individuals to have the test. Nonetheless, the responsibility of the physician to inform and recommend $\mathrm{CRC}$ screening cannot be discounted, as they play an important role in facilitating access and equity to increase uptake. Indeed, there is an ongoing need to enhance socio-cultural training of health care providers, especially family physicians to address the gap in CRC screening uptake at the population level. Key recommendations from several studies included more physician engagement in the provision of information, and further physician education to understand cultural beliefs, customs, and needs (Ahmad et al., 2011; Thomas et al., 2005). As well, the current focus of attention on enhancing the collaboration between primary care and public health has the potential to improve current gaps in cancer screening experienced by ethnic and immigrant minorities (Institute of Medicine, 2012).

\section{Limitations}

There were a number of limitations in this study. Participants were recruited from temples and community centres in a mid-sized urban city in Canada, and may differ from those who do not attend these social activities or reside in different settings. Participants also had access to universal health care and most had a family physician, which may differ from populations in other countries with different health system structures or processes. The sample of unscreened participants in this study also may differ from other under-screened or never screened SA immigrants in other settings. SA immigrants who agreed to participate were highly motivated and may differ from those who did not. The mixing of the focus groups with screened and unscreened participants may have also influenced some participants who may not have felt comfortable disclosing information within a group setting. Several strengths of the study were the diversity of the focus group sample and the fact that groups were conducted in participantst' preferred languages with special attention to reduce power differences between the investigator and participants. 


\section{Conclusion}

This study is to our knowledge among the first to specifically examine CRC screening behaviours from the perspective of SA immigrants in North America. Focus groups enabled the exploration of beliefs and attitudes towards CRC and screening among a diverse SA immigrant population. Novel findings that can influence screening uptake included: SA bowel practices, experiential learning in focus groups, community-based strategies, and the physician role in screening access. These findings provide insights into socio-cultural context and beliefs, knowledge, barriers, and strategies to promote CRC screening among unscreened and screened SA immigrant communities. Findings such as the contribution of bowel practices require further explanation to assess their prevalence and importance in diverse SA immigrant populations.

This study also demonstrated that among a diverse sample, the majority of unscreened SA immigrants were eager to learn and take up CRC screening. Sharing experiences and stories of cancer and screening fostered peer learning in the focus groups for unscreened participants. Unscreened participants who heard about screening for the first time saw its potential to decrease worry, were motivated to gain further knowledge, and ask their physician about the test. This was an important finding as it inadvertently promoted screening. As well, participants felt that community education in common gathering places, such as temples and community centres were strategies among SA immigrants that considered collectivist values, and in turn, could increase knowledge and screening. For some, this method was preferred over written material, thus, overcoming the literacy barrier.

Physicians are influential in providing information of the risks of CRC, explaining the rationale for screening, and facilitating access to the test; all important elements to increase uptake. While the physician cannot enforce screening, he/she is responsible for conveying best practices with the aim of increasing screening uptake among under screened SA immigrant and other multilingual and ethnic populations. For some screened participants, they took up screening without a full explanation from their physician, another novel finding. Therefore, future research would be useful to explore if this is the case in a larger population of SA immigrants. Future efforts should also focus on the development of community-based strategies involving SA immigrants, family physicians, and other health care providers to increase uptake of CRC screening. Outcomes of these interventions could then be evaluated through further research.

\section{References}

Aday, L.A. and Cornelius, L.J. (2006), Designing and Conducting Health Surveys: A Comprehensive Guide, 3rd ed., Jossey-Bass, San Francisco, CA.

Ahmad, F. (2012), "South Asian", in Loue, S. and Sajatovic, M. (Eds), Encyclopaedia for Immigrant Health, Springer, New York, NY, pp. 1371-5.

Ahmad, F., Mahmood, S., Pietkiewicz, I., McDonald, L. and Ginsburg, O. (2011), "Concept mapping with South Asian immigrant women: barriers to mammography and solutions", Journal of Immigrant \& Minority Health, Vol. 14 No. 2, pp. 242-50.

Ahmad, F., Shik, A., Vanza, R., Cheung, A., George, U. and Stewart, D.E. (2004), "Population health promotion strategies among Chinese and east Indian immigrant women", Women \& Health, Vol. 40 No. 1, pp. 21-40.

Austin, K.L., Power, E., Solarin, I., Atkin, W.S., Wardle, J. and Robb, K.A. (2009), "Perceived barriers to flexible sigmoidoscopy screening for colorectal cancer among UK ethnic minority groups: a qualitative study", Journal of Medical Screening, Vol. 16 No. 4, pp. 174-9.

Banning, M. and Hafeez, H. (2010), "A two-center study of Muslim women's views of breast cancer and breast health practices in Pakistan and the UK", Journal of Cancer Education, Vol. 25 No. 3, pp. 349-53.

Bauerle Bass, S., Gordon, T.F., BurthRuzek, S., Wolak, C., Ward, S., Paranjape, A., Lin, K., Meyer, B. and Ruggieri, D.G. (2011), "Perceptions of colorectal cancer screening in Urban African American clinic patients: differences by gender and screening status", Journal of Cancer Education, Vol. 26 No. 1, pp. 121-8.

Bottorff, J.L., Johnson, J.L., Venables, L.J., Grewal, S. and Popa, N. (2001), "Voices of immigrant South Asian women: expressions of health concerns", Journal of Health Care for the of Poor and Underserved, Vol. 12 No. 4, pp. 392-403. 
Boxwala, F.L., Bridgemohan, A., Griffith, D.M. and Soliman, A.S. (2010), "Factors associated with breast cancer screening in Asian Indian women in metro-detroit”, Journal of Immigrant Minority Health, Vol. 12 No. 4, pp. 534-43.

Braun, V. and Clarke, V. (2006), "Using thematic analysis in qualitative research in psychology", Qualitative Research in Psychology, Vol. 3 No. 2, pp. 77-101.

Canadian Task Force on Preventive Health Care (CTFPHC) (2001), "Colorectal cancer screening. Recommendation statement from the Canadian task force on preventive health care", Canadian Medical Association Journal, Vol. 165 No. 2, pp. 206-8.

Cancer Care Ontario (2014), "Colorectal cancer screening", Cancer Care Ontario, Toronto, Ontario, available at: www.cancercare.on.ca/pcs/screening/coloscreening (accessed June 10, 2014).

Choudhry, U.K. (1998), "Health promotion among immigrant women from India living in Canada", Journal of Nursing Scholarship, Vol. 30 No. 3, pp. 269-74.

Corbin, J. and Strauss, A. (2008), Basics of Qualitative Research, 3rd ed., Sage, Los Angeles, CA.

Esposito, N. (2001), "From meaning to meaning: the influence of translation techniques on non-English focus group research", Qualitative Health Research, Vol. 11 No. 4, pp. 568-79.

Glaser, B. (1978), Theoretical Sensitivity, Sociology Press, Mill Valley, CA.

Glaser, B. (1998), Doing Grounded Theory: Issues and Discussions, Sociology Press, Mill Valley, CA.

Glaser, B.G. and Strauss, A. (1967), The Discovery of Grounded Theory: Strategies for Qualitative Research, Aldine, New York, NY.

Glenn, B.A., Chawla, N., Surani, Z. and Bastani, R. (2009), "Rates and socio-demographic correlates of cancer screening among SA's”, Journal of Community Health, Vol. 34 No. 2, pp. 113-21.

Gupta, A., Kumar, A. and Stewart, D.E. (2002), "Cervical cancer screening among South Asian women in Canada: the role of education and acculturation", Health Care Women International Journal, Vol. 23 No. 2, pp. 123-34.

Hislop, T.G., Bajdick, C.D., Saroa, S.R., Yeole, B.B. and Barroetavena, M.C. (2007), "Cancer incidence in Indians from three areas: Delhi and Mumbai, India, and British Columbia, Canada", Journal of Immigrant and Minority Health, Vol. 9 No. 3, pp. 221-7.

Honein-Abou Haidar, G.N., Baxter, N.N., Moineddin, R., Urbach, D.R., Rabeneck, L. and Bierman, A.S. (2013), "Trends and inequities in colorectal cancer screening participation in Ontario, Canada, 2005-2011", Cancer Epidemiology, Vol. 37 No. 6, pp. 946-56.

Hossain, A., Sehbai, A., Abrahan, R. and Abraham, J. (2008), "Cancer health disparities among Indian and Pakistani immigrants in the United States: a surveillance, epidemiology, and end results-based study from 1988-2003", Cancer, Vol. 113 No. 6, pp. 1423-30.

Hou, S.-I., Sealy, D.-A. and Kabiru, C.W. (2011), "Closing the disparity gap: cancer screening interventions among Asians: a systematic literature review", Asian Pacific Journal of Cancer Prevention, Vol. 12 No. 11, pp. 3133-9.

Institute of Medicine (2012), Primary Care and Public Health: Exploring Integration to Improve Population Health, The National Academies Press, Washington, DC.

Jain, R.V., Mills, P.K. and Parikh-Patel, A. (2005), "Cancer incidence in the South Asian population in California", Journal of Carcinogen, Vol. 4 No. 1, pp. 13-21.

Jemal, A., Bray, F., Center, M.M., Ferlay, J., Ward, E. and Forman, D. (2011), "Global cancer statistics", CA: A Cancer Journal for Clinicians, Vol. 61 No. 2, pp. 69-91.

Kitzinger, J. (1994), "The methodology of focus groups: the importance of interaction between research participants", Sociology of Health and IIIness, Vol. 16 No. 1, pp. 103-21.

Krueger, R.A. (1994), Focus Groups: A Practical Guide for Applied Research, 2nd ed., Sage, Thousand Oaks, CA.

Lee, H.Y., Ju, E., Vang, P.D. and Lundquist, M. (2010a), "Breast and cervical cancer screening among Asian American women and Latinas: does race/ethnicity matter?", Journal of Women's Health, Vol. 19 No. 10, pp. 1877-84.

Lee, H.Y., Lundquist, M., Ju, E., Luo, X. and Townsend, A. (2011), "Colorectal cancer screening disparities in Asian Americans and Pacific Islanders: which groups are most vulnerable?", Ethnicity \& Health, Vol. 16 No. 6, pp. 501-18. 
Lee, S., Martinez, G., Ma, G.X., Hsu, C.E., Robinson, E.S., Bawa, J. and Juon, H.-S. (2010b), "Barriers to health care access in 13 Asian American communities", American Journal of Health Behaviour, Vol. 34 No. 1, pp. 21-30.

Lincoln, Y.S., Lynham, S.A. and Guba, E.G. (2011), "Paradiagmatic controversies, contradictions, and emerging confluences, revisited", in Denzin, K. and Lincoln, Y.S. (Eds), Handbook of Qualitative Research, 4th ed., Sage, Thousand Oaks, CA, pp. 97-128.

Morgan, D.L. and Krueger, R.A. (1998), The Focus Group Kit, Vols 1-6, Sage, Thousand Oaks, CA.

Oelke, N.D. and Vollman, A.R. (2007), "Inside and outside: Sikh women's perspectives on cervical cancer screening", Canadian Journal of Nursing Research, Vol. 39 No. 1, pp. 174-89.

Ontario Ministry of Health and Long Term Care (MOHLC) (2012), "Colon cancer check. What is the colon cancer check program", MOHLC, Ottawa, Ontario, available at: www.health.gov.on.ca/en/public/programs/ coloncancercheck/program.aspx (accessed August 6, 2014).

Quan, H., Fong, A., De Coster, C., Wang, J., Musto, R., Noseworthy, T.W. and Ghali, W.A. (2006), "Variation in health services utilization among ethnic populations", Canadian Medical Association Journal, Vol. 174 No. 6, pp. 787-91.

Rastogi, T., Devesa, S., Mongtani, P., Mathew, A., Cooper, N., Kao, R. and Sinha, R. (2008), "Cancer incidence rates among South Asians in four geographic regions: India, Singapore, UK and US", International Journal of Epidemiology, Vol. 37 No. 1, pp. 147-60.

Robb, K.A., Solarin, I., Power, E., Atkin, W. and Wardle, J. (2008), "Attitudes to colorectal cancer screening among ethnic minority groups in UK”, BMC Public Health, Vol. 8 No. 1, pp. 34-44.

Social Planning and Research Council (SPRC) of Hamilton (2009), "Community profiles: Hamilton", Social Planning and Reserach Council (SPRC) of Hamilton, Ontario, available at: www.sprc.hamilton.on.ca/Reports/ pdf/Hamilton-Update-FINAL.pdf (accessed June 10, 2014).

Somanchi, M., Juon, H.S. and Rimal, R. (2010), "Predictors of screening mammography among Asian Indian American women: a cross-sectional study in the Baltimore-Washington Metropolitan area", Journal of Women's Health, Vol. 19 No. 3, pp. 433-41.

Szczepura, A., Price, C. and Gumber, A. (2008), "Breast and bowel cancer screening uptake patterns over 15 years for South Asian ethnic minority populations, corrected for differences in socio-demographic characteristics", BioMed Central Public Health, Vol. 8 No. 1, p. 15.

Szczepura, A., Johnson, M., Orbell, S., Gumber, A., O'Sullivan, I., Clay, D. and Owen, D. (2003), "Ethnicity: UK colorectal cancer screening pilot", final report, Cancer screening programmes, National Health Services, Sheffield, available at: www.cancerscreening.nhs.uk/bowel/ethnicityfinalreport (accessed May 20, 2014).

Thomas, V.N., Saleem, T. and Abraham, R. (2005), "Barriers to effective uptake of cancer screening among black and minority ethnic groups", International Journal of Palliative Nursing, Vol. 11 No. 11, pp. 562-71.

Thomson, M.D. and Hoffman-Goetz, L. (2010), "Colon cancer information preferences of English-as-asecond-language immigrant women: does language of interview matter", Journal of Cancer Education, Vol. 25 No. 2, pp. 229-35.

Tran, K., Kaddatz, J. and Allard, P. (2005), "South Asians in Canada: unity through diversity", Catalogue No. 11-008, Canadian Social Trends, Statistics Canada, Ottawa, Ontario, available at: www5.statcan.gc.ca/ bsolc/olc-cel/olc-cel?catno =11-008-X20050028455\&lang = eng (accessed August 6, 2014).

US Preventive Services Task Force (2008), "Screening for colorectal cancer: US Preventive Services Task Force Recommendation Statement”, Annals of Internal Medicine, Vol. 156 No. 12, pp. 880-91.

Westaby, J.D. (2005), "Behavioral reasoning theory: identifying new linkages underlying intentions and behaviour”, Organizational Behaviour and Human Decision Processes, Vol. 98 No. 2, pp. 97-120.

Winawer, S.J. (2005), "Screening of colorectal cancer", Surgical Oncology Clinics of North America, Vol. 14 No. 4, pp. 699-722.

\section{Appendix. Focus group interview guide}

1. Do you feel like you know something about colorectal cancer?

2. Is colorectal cancer a concern for you?

3. Does anybody know or has anyone heard about colorectal cancer screening?

4. Has anyone you know had a colorectal cancer test? 
5. How do you feel about colorectal cancer screening in general?

6. What do you think are the benefits of doing colorectal cancer screening?

7. What are the disadvantages/bad things about doing colorectal cancer screening?

8. In your family or network of friends, do you have those who would support you in having colorectal cancer screening?

9. Are there people in your life who may not support colorectal cancer screening?

10. What are the things that make it easy for you to have colorectal cancer screening?

11. What are the things that make it hard to have colorectal cancer screening?

12. What are the reasons that you have NOT or DO NOT want to have colorectal cancer screening?

13. What are the reasons that you DID have or WOULD have colorectal cancer screening?

14. For people who had screening: Think back on the most recent experience.

a. What test was it?

b. How did you feel about the process?

c. What concerns or fears did you have?

d. Where there any surprises for you? If yes, what?

e. Was there anything that you think would have made the experience more positive?

15. What would you tell someone who was debating whether or not to be screened?

\section{Author affiliations}

Joanne Crawford is Lecturer at the Department of Nursing, Brock University, St Catharines, Canada and a PhD Candidate at the Lawrence S. Bloomberg Faculty of Nursing, University of Toronto, Toronto, Canada.

Farah Ahmad is Associate Professor at the School of Health Policy and Management, Faculty of Health, York University, Toronto, Canada.

Dorcas E. Beaton is Director and Scientist at Musculoskeletal Health and Outcomes Research, Li Ka Shing Knowledge Institute, St Michael's Hospital, Toronto, Canada; Scientist, Measurement Stream, Institute for Work and Health, Toronto, Canada and Associate Professor at the Department of Occupational Science and Occupational Therapy, Rehabilitation Sciences Institute, and the Institute of Health Policy, Management and Evaluation, University of Toronto, Toronto, Canada.

Arlene S. Bierman is a Scientist at the Keenan Research Centre, Li Ka Shing Knowledge Institute, St Michael's Hospital, Toronto, Canada and Professor at Lawrence S. Bloomberg Faculty of Nursing, Institute of Health Policy, Management and Evaluation, Medicine, and Public Health, University of Toronto, Toronto, Canada.

\section{Corresponding author}

Joanne Crawford can be contacted at: joanne.crawford@brocku.ca

For instructions on how to order reprints of this article, please visit our website:

www.emeraldgrouppublishing.com/licensing/reprints.htm

Or contact us for further details: permissions@emeraldinsight.com 
Reproduced with permission of the copyright owner. Further reproduction prohibited without permission. 